\title{
ШВИДКИЙ АЛГОРИТМ АДАПТАЦІї ПІ- РЕГУЛЯТОРА
}

Fast adaptation algorithm for pi controller.

Шумигай Д.А., к.т.н. (Shumyhai D., PhD) ${ }^{1}$, Ладанюк А.П., д.т.н., проф. (Ladanyuk А., prof.) ${ }^{2}$, Смітюх Я.В.,к.т.н., доц. (Smityuh Y., PhD) ${ }^{3}$

1, 2, 3 Національний університет харчових технологій, Київ

E-mail: ${ }^{1}$ shumygai@gmail.com

Copyright (C) 2014 by author and the journal "Automation technological and business - processes".

This work is licensed under the Creative Commons Attribution International License (CC BY).

http://creativecommons.org/licenses/by/4.0/

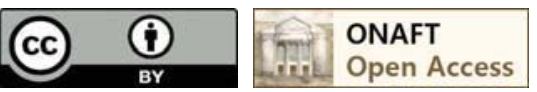

\section{Анотація}

На промислових установках основа економічного ефекту від автоматизованих систем керування - якість роботи системи регулювання. Для підвищення якості автоматизованих систем керування повинні бути знайдені відповідні параметри регулятора, але підвищення точності приводить до зменшення запасу стійкості, тому в складних системах оператори намагаються зменшити налаштування (тобто встановити "слабкі настройки"), щоб система працювала у всіх режимах. "Слабкі настройки" контурів на процес - основний недолік діючих систем регулювання, що знижус прибуток підприсмств. Першопричиною ослаблених налаштувань і низької якості функціонування систем регулювання є досить часті зміни характеристик об'єкта, які викликані змінним режимом роботи об'єктів, властивостями регулювальних органів, взаємозалежністю контурів в багатовимірних системах. В умовах експлуатації сдиний вихід - послабити настройки, домагаючись зниження, таким чином, взаємовпливу контурів, забезпечення необхідного запасу стійкості при будь-яких можливих режимах роботи об'єкта. Якість роботи систем при цьому очевидно гірше, а прибуток менше. В статті наводяться можливі підходи, які дозволяють збільшити ефективність функціонування автоматичних систем керування та описано розроблений алгоритм адаптації ПІ-регулятора на основі аналізу статистичних даних.

\section{Ключові слова}

Адаптація, ідентифікація, статистичний аналіз, ПІ-регулятор, ефективність системи керування.

Annotation

Quality of the automatic control is the basis of economic effect of industrial control systems. The appropriate regulator settings should be found to improve the quality of automated control systems, but improved accuracy results in the reduction of stability margin, that's why operators try to reduce setttings in complex systems (ie, set the "weak setting"),so the system could worke in all modes. Controller's "low (all-mode) tuning" is the main disadvantage of existing control systems, which reduces profits. Frequent changes of plant parameters are the prime cause of low quality tuning and reduced efficiency of control systems. These changes are caused by changeable mode of plants, loop interdependence in multidimensional systems. In terms of operating the only one way is to ease settings, achieving reduction of loop interdependence, ensuring adequate stability margin in all possible modes of operation. The quality of work with such tuning is obviously worse and the profit is less. The article presents possible approaches that can increase the efficiency of automatic control systems and describes the adaptation algorithm for PI controller based on an analysis of statistical data.

Key words

Adaptation, identification, statistical analysis, PI controller, efficiency of the control system. 


\section{Вступ}

Техніко-економічні показники функціонування технологічних об’єктів (технологічних процесів, агрегатів та комплексів) значною мірою залежать від якості процесів керування та оперативності прийняття управлінських рішень. Динамічні властивості технологічних об'єктів характеризуються нелінійністю, нестаціонарністю, наявністю кількох цілей, а також численними внутрішніми перехресними зв'язками між регульованими координатами.

Для систем 3 істотно змінювальними характеристиками об'єкта можливі дві стратегії, що призводять до нормальної експлуатації системи автоматичного регулювання (САР), тобто дозволяють виключити постійні відключення регуляторів і перехід на ручне керування: використання "слабких", але всережимних налаштувань або забезпечення адаптації налаштувань регуляторів в системах до мінливих характеристик об'єктів [1].

В статті проаналізовані методи отримання налаштувань регулятора для забезпечення стійкості та якості системи регулювання, та розглядається запропонований метод адаптації ПІ-регулятора.

Розробка алгоритмічного забезпечення адаптації ПІ-регулятора

Всі види автоматичної настройки використовують три принципово важливих етапи: ідентифікація об'єкта, розрахунок параметрів регулятора, настройка регулятора [2]. Часто кінцевий етап включає етап підстроювання (заключна оптимізація настройки). Оптимізація налаштування необхідна у зв'язку з тим, що методи розрахунку параметрів регулятора за формулами не враховують нелінійності об'єкта, зокрема, завжди присутню нелінійність типу «обмеження», а ідентифікація параметрів об'єкта виконується з деякою погрішністю. Підстроювання регулятора може бути пошуковим (без ідентифікації об'єкта, шляхом пошуку оптимальних параметрів) і безпошуковим (з ідентифікацією). Пошукова ідентифікація базується зазвичай на правилах або на ітераційних алгоритмах пошуку мінімуму критерію оптимальності. Найбільш поширений пошук оптимальних параметрів за допомогою градіснтного метода: знаходять похідні від критерію оптимальності з параметрами ПІ-регулятора, які є компонентами вектора градієнта, а далі проводиться зміна параметрів у відповідності з напрямком градієнта.

Структурна схема самоналаштовуваної системи наведена на рис. 1.

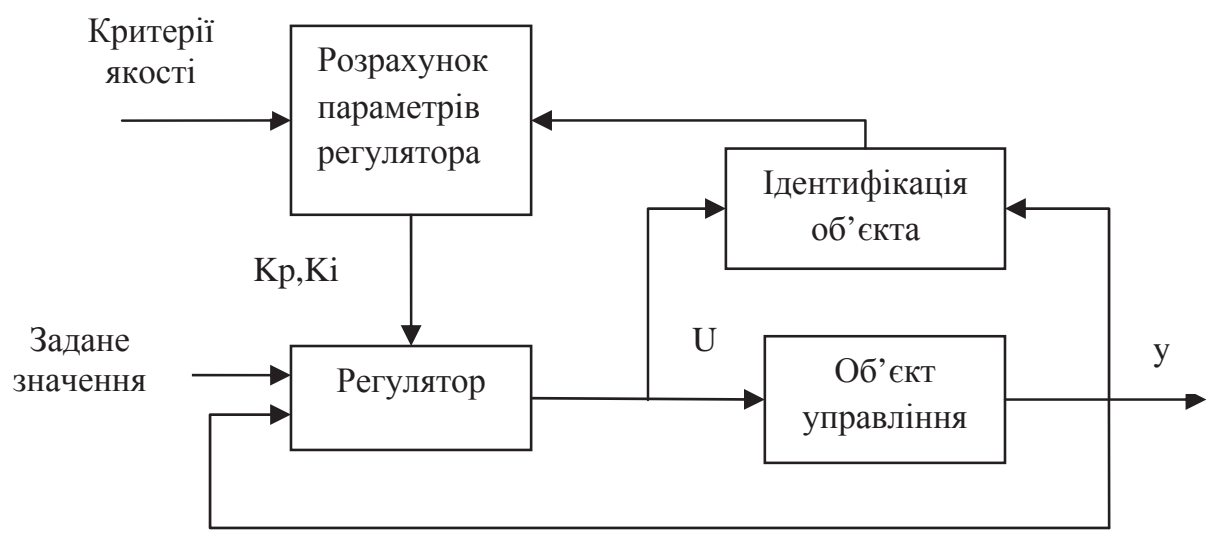

Рис. 1 - Загальна структура системи з автоматичним налаштуванням

Важливо підкреслити, що незважаючи на наявність автоматичного підстроювання, контролер може не дати необхідної якості регулювання з причин, не залежних від якості закладених в нього алгоритмів. Наприклад, об'єкт керування може бути погано спроектований (залежні контури регулювання, велике запізнення, високий порядок об'єкта); об'єкт може бути нелінійним; датчики можуть бути розташовані не в тому місці, де потрібно, і мати поганий контакт з об'єктом, рівень перешкод в каналі вимірювання може бути неприпустимо великим; чутливість датчика може бути недостатньо високою; джерело вхідного впливу на об'єкт може мати дуже велику інерційність або гістерезис; можуть бути також помилки в монтажі системи, погане заземлення, обриви провідників і т.д. [2]

Зазвичай розрахунок параметрів регулятора за формулами не може дати оптимальної настройки, оскільки аналітично отримані результати грунтуються на сильно спрощених моделях об'єкта. Зокрема, в них не враховується завжди присутня нелінійність типу «обмеження» для керувального впливу. Крім того, моделі використовують параметри, ідентифіковані з деякою похибкою, тому після розрахунку параметрів регулятора бажано зробити його підстроювання, яке можна виконати на основі правил, які використовуються для ручного налаштування. Ці правила отримані з досвіду, теоретичного аналізу та чисельних експериментів. Вони зводяться до наступного [2]:

- збільшення коефіцієнта пропорційності підвищує швидкодію і знижує запас стійкості;

• зі зменшенням інтегральної складової помилка регулювання з часом зменшується швидше;

- зменшення постійної інтегрування зменшує запас стійкості;

- збільшення диференціальної складової збільшує запас стійкості і швидкодію.

Запропонована система доналаштування параметрів регулятора для одноконтурної системи буде працювати в режимі реального часу на об’єкті. Система автоматично аналізує поточний стан системи керування за обраний час 
(для цього необхідно виконати статистичний контроль вхідних та вихідних змінних трендів) і пропонує оператору яким чином за допомогою зміни параметрів регулятора покращити якість регулювання.

Для статистичного аналізу формується система, яка являє собою візуальне середовище, призначене для забезпечення стабільності параметрів та діагностики порушень за результатами статистичного контролю багатопараметричного ТП з метою попередження виходу контрольованих показників за допустимі межі.

Система статистичного контролю дозволяе в оперативному режимі оцінювати стабільність багатопараметричного процесу і відслідковувати порушення процесу для прийняття керувальної дії [3].

Додатково до обробки статистичних даних загалом та часових рядів можна використати дескриптивний статистичний аналіз рядів спостережень, який передбачає визначення основних вибіркових характеристик розподілення ряду, а саме:

- вибіркове середнє:

$$
\bar{X}=\frac{1}{n} \sum_{i=1}^{n} X_{i}
$$

де $X_{n}$ - ряд спостережень досліджуваної змінної;

- вибіркову дисперсію:

$$
D(x)=\frac{1}{n} \sum_{i=1}^{n}\left(x_{i}-\bar{x}\right)^{2}
$$

- середньоквадратичне відхилення (СКВ):

$$
\sigma=\sqrt{D(x)}
$$

- коефіцієнт варіації:

$$
V=\frac{\sigma}{\bar{x}}
$$

- коефіцієнт асиметрії:

$$
A s=\frac{1}{n}\left(\sum_{i=1}^{n}\left(x_{i}-\bar{x}\right)^{3}\right) / \sigma^{3}
$$

- коефіцієнт ексцесу:

$$
E x=\frac{1}{n}\left(\sum_{i=1}^{n}\left(x_{i}-\bar{x}\right)^{4}\right) / \sigma^{4}-3
$$

Система доналаштування параметрів регулятора відображає поточні налаштування регулятора та запропоновані для покращення якості регулювання, а також статистичний аналіз контрольованого перехідного процесу.

Для розробки алгоритму адаптації ПІ-регулятора було проведено аналіз системи автоматичного регулювання. Математична модель об’єкта (бражної колони) представлена на рис.2. Вхідними сигналами є витрата охолоджувальної води $(\mathrm{G})$, витрата пари $(\mathrm{V})$, витрата бражки (F); вихідними - температура охолодженої води після конденсатора (Тоth), температура верху колони (Tv), тиск верху колони (Pv), тиск низу (Pn). Для реалізації адаптивного алгоритму настройки регулятора обрано контур регулювання тиску низу колони. 


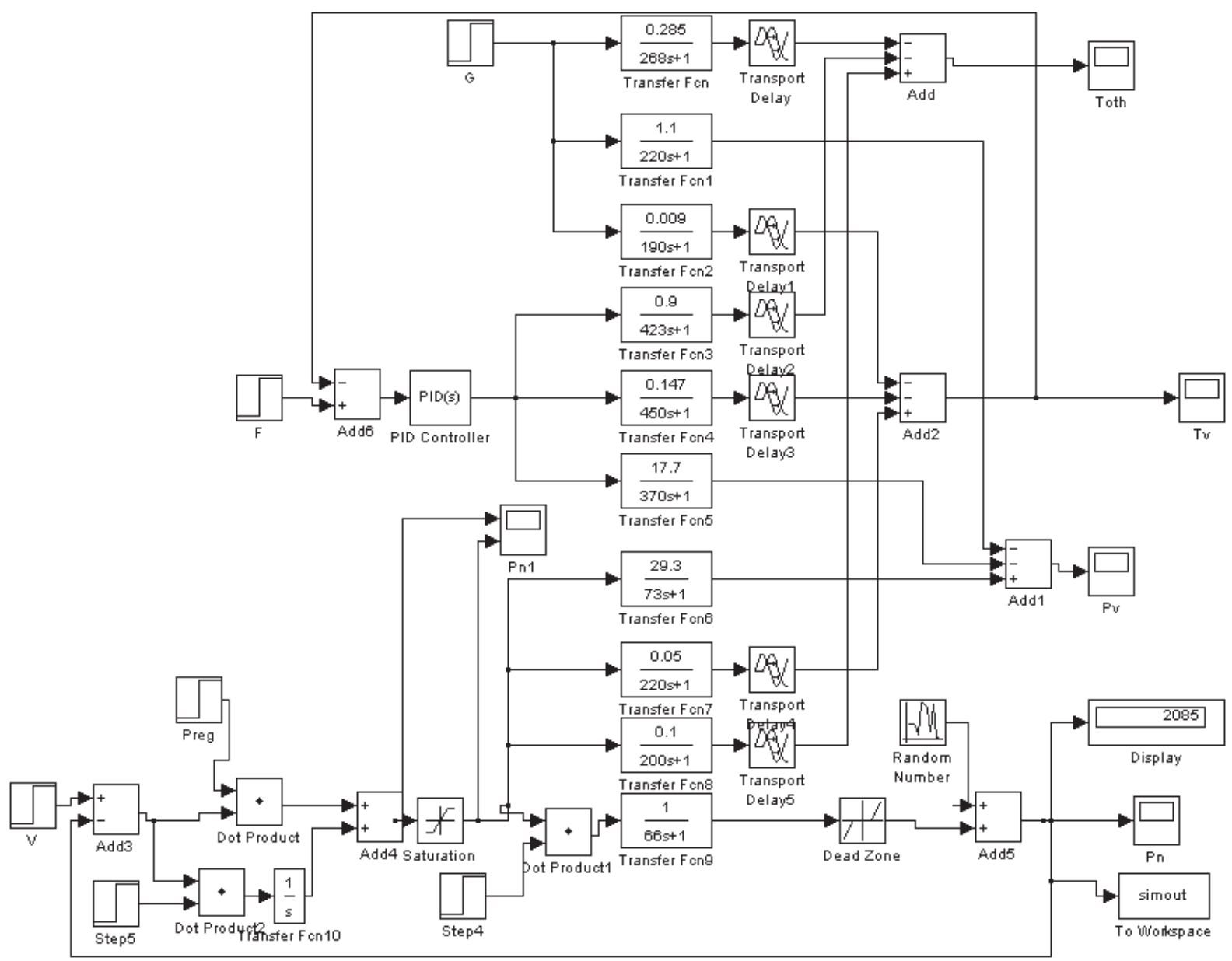

Рис. 2 - Система автоматичного регулювання бражної колони

Попередньо проведено досліди при суттєвих збуреннях, які відображають вплив зміни параметрів регулятора на якість перехідного процесу (табл.1).

\begin{tabular}{|l|l|l|c|} 
Табл. 1 - Вплив налаштвань ПІ-регулятора на якість регулювання \\
\hline Kр & Ki & $\begin{array}{c}\text { Математичне } \\
\text { сподівання, } \\
\text { мм.вод.ст. }\end{array}$ & $\begin{array}{c}\text { Середньоквадрати } \\
\text { мн.вод.ст. }\end{array}$ \\
\hline 2 & 0,02 & 2063,411 & 80,02136 \\
\hline 1 & 0.02 & 2010,451 & 74,56573 \\
\hline 0,8 & 0,02 & 2006,497 & 75,0804 \\
\hline 0,1 & 0,02 & 2002,46 & 82,39869 \\
\hline 0,02 & 0,02 & 1994,359 & 87,38202 \\
\hline 0,8 & 0,0001 & 2002,391 & 74,80111 \\
\hline 0,8 & 0,001 & 2007,121 & 74,83759 \\
\hline 0,8 & 0,006 & 2023,412 & 81,71838 \\
\hline 0,8 & 0,02 & 2004,496 & 82,83929 \\
\hline 0,8 & 0,1 & 2006,788 & 75,68891 \\
\hline 0,8 & 0,2 & 2004,287 & 77,14621 \\
\hline 0,8 & 0,8 & 1981,761 & 88,97214 \\
\hline
\end{tabular}

Алгоритм розрахунку налаштувань ПІ-регулятора (рис. 2) є неперервним і полягає в постійному аналізі поточного стану системи регулювання. Після знаходження математичного сподівання та середньоквадратичного 
відхилення, відбувається перевірка чи не виходить значення середньоквадратичного відхилення за допустиме значення (у нашому випадку 50 мм.вод.ст.) та перевірка відхилення математичного сподівання від заданого значення.

Розрахунок значень Кр та Кі відбувається за отриманими формулами: за умови, що середньоквадратичне відхилення перевищує допустиме значення:

$$
\begin{gathered}
K r n=K r+K r(X z-M) / M * K 1+K r *\left(\sigma-\sigma_{\max }\right) / \sigma * K 2 \\
K i n=K r n / K 3-\left(\sigma-\sigma_{\max }\right) / \sigma * K 4
\end{gathered}
$$

та за умови, що середньоквадратичне відхилення не перевищує допустиме значення:

$$
\begin{gathered}
K r n=K r+K r(X z-M) / M * K 1 \\
K i n=K r n / K 3
\end{gathered}
$$

$K r n$ - нове значення Кр; $K r$ - поточне значення Кр; $M$ - математичне сподівання; $X z$ - задане значення; $\sigma$ середньоквадратичне відхилення; $\sigma_{\max }$-максимально допустиме середньоквадратичне відхилення; Kin - нове значення Кi;

$K 1, K 2, K 3, K 4$ - допоміжні коефіцієнти, які залежать від характеристик досліджуваного об'єкта. В нашому випадку $K 1=100 ; K 2=0,5 ; K 3=100 ; K 4=0,002$.

На момент розрахунку система враховує попередні значення Кр та Кі.

Дослідження ефективності запропонованого алгоритму проводилось при дії суттєвих та несуттєвих збурень при різних початкових значеннях налаштувань ПІ-регулятора. Отриманий результат (табл. 2) свідчить, що у всіх випадках

\begin{tabular}{|c|c|c|c|c|c|c|c|c|}
\hline \multicolumn{9}{|c|}{ Суттєве збурення } \\
\hline № & Kp & $\mathrm{Ki}$ & $\begin{array}{l}\text { Мат } \\
\text { Спод, } \\
\text { мм.вод.ст. }\end{array}$ & $\begin{array}{l}\text { Серед } \\
\text { Відх, } \\
\text { мм.вод.ст. }\end{array}$ & $\begin{array}{l}\text { Нове } \\
\text { Кр }\end{array}$ & $\begin{array}{c}\text { Нове } \\
\text { Ki }\end{array}$ & $\begin{array}{l}\text { Нове Мат } \\
\text { Спод, } \\
\text { мм.вод.ст. }\end{array}$ & $\begin{array}{c}\text { Нове Серед } \\
\text { Відх, } \\
\text { мм.вод.ст. }\end{array}$ \\
\hline 1 & 0.9 & 0.02 & 2006.5946 & 77.8884 & 0.76534 & 0.0069373 & 2006.255 & 76.4563 \\
\hline 2 & 0.3 & 0.2 & 1988.6665 & 186.8852 & 0.58084 & 0.0043435 & 2001.7084 & 75.4724 \\
\hline 3 & 0.9 & 0.002 & 1978.2667 & 77.4809 & 2.0483 & 0.019774 & 2008.5217 & 84.2255 \\
\hline 4 & 0.3 & 0.02 & 2005.1747 & 73.5495 & 0.27061 & 0.0020657 & 1989.4868 & 73.4524 \\
\hline 5 & 0.5 & 0.002 & 1977.2575 & 75.698 & 1.16 & 0.010921 & 2007.5598 & 78.3699 \\
\hline 6 & 0.4 & 0.2 & 2004.7723 & 114.626 & 0.41754 & 0.0030478 & 1996.6872 & 74.463 \\
\hline 7 & 0.9 & 0.2 & 2012.439 & 80.5709 & 0.51445 & 0.0043856 & 2002.6196 & 74.9697 \\
\hline \multicolumn{9}{|c|}{ Несуттєве збурення } \\
\hline 8 & 0.9 & 0.2 & 2005.679 & 38.2108 & 0.64517 & 0.0064517 & 2005.5168 & 34.3407 \\
\hline 9 & 0.4 & 0.2 & 2007.6504 & 88.1263 & 0.3341 & 0.0024757 & 1993.1426 & 34.3912 \\
\hline 10 & 0.5 & 0.002 & 1977.0404 & 35.797 & 1.0807 & 0.010807 & 2007.562 & 36.1174 \\
\hline 11 & 0.9 & 0.002 & 1976.4101 & 35.9277 & 1.9742 & 0.019742 & 2009.1804 & 39.4951 \\
\hline 12 & 0.3 & 0.2 & 1983.7282 & 184.214 & 0.65537 & 0.0050965 & 2003.369 & 34.3834 \\
\hline 13 & 0.3 & 0.02 & 2005.0565 & 33.2994 & 0.22434 & 0.0022434 & 1998.1083 & 33.5407 \\
\hline 14 & 0.9 & 0.02 & 2005.7475 & 35.2165 & 0.64211 & 0.0064211 & 2005.4946 & 34.3288 \\
\hline
\end{tabular}
відбулось зменшення відхилення від заданого значення та зменшився розкид точок навколо середнього значення, що свідчить про покращення якості регулювання. Суттєве покращення відбулось у дослідах 2,6,9,12.

Табл. 2 - Вплив адаптованих налаштувань ПІ-регулятора на якість регулювання 


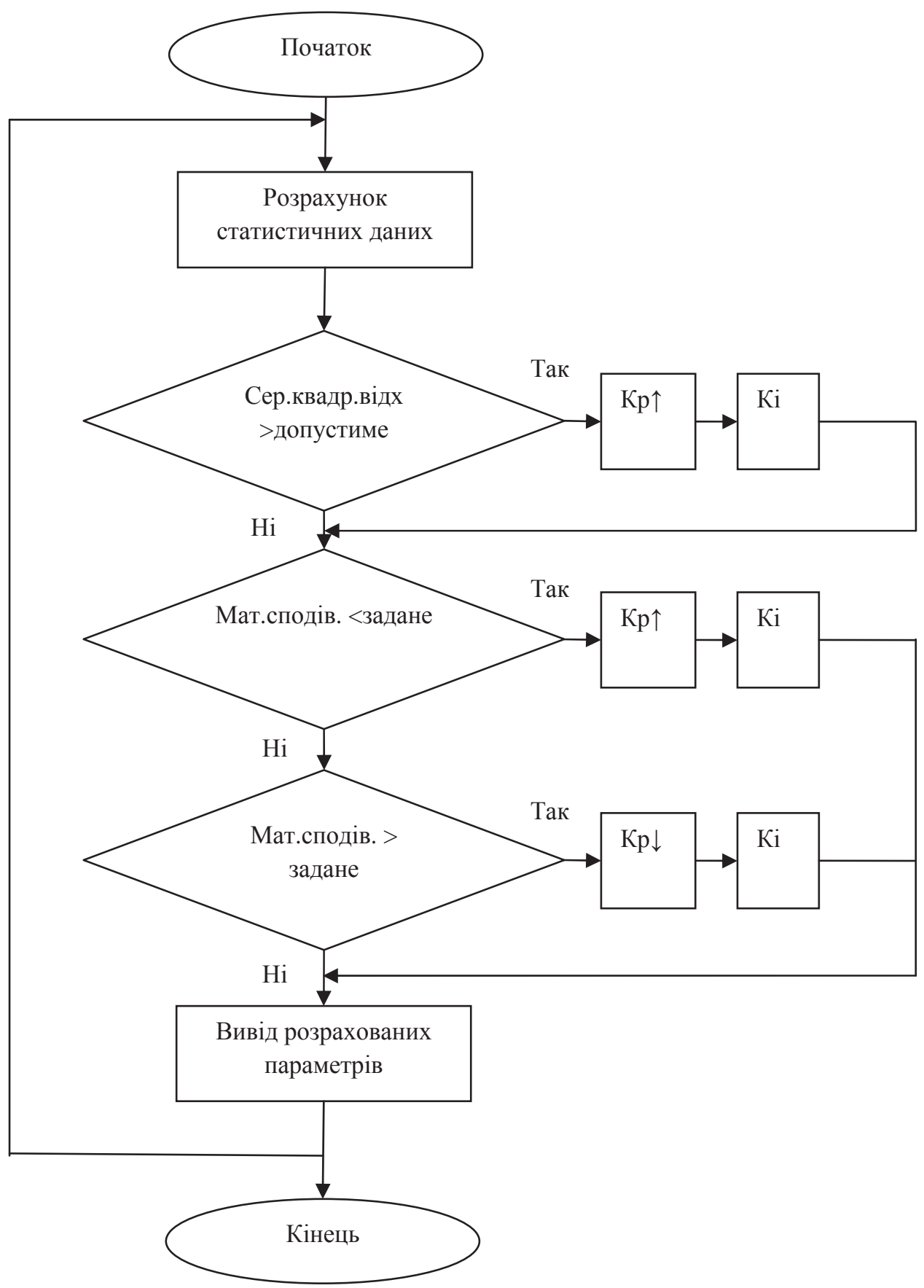

Рис. 2 - Алгоритм адаптації ПІ-регулятора

Наведено один з перехідних процесів (рис.3), отриманих при змінюванні налаштувань.

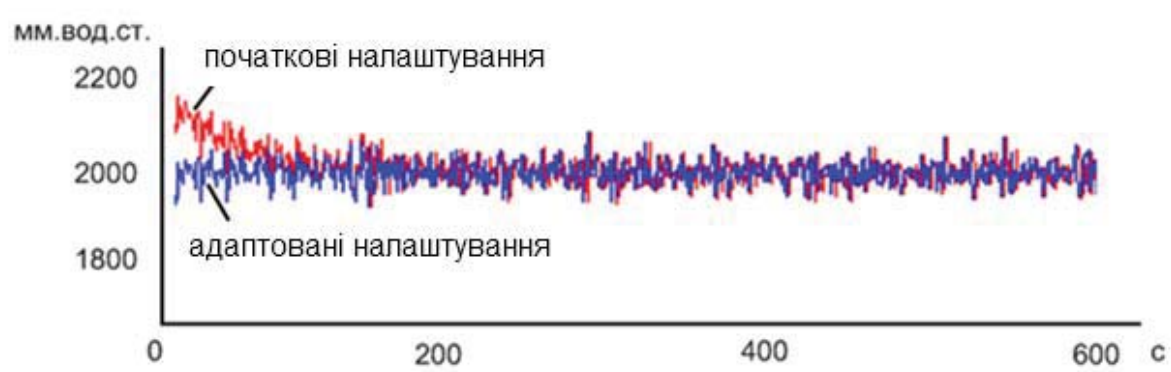

Рис 3 - Перехідний процес при різних налаштуваннях ПІ-регулятора 
Для використання розробленого алгоритму адаптації попередньо параметри регулятора визначаються одним із існуючих методів, далі використовуючи запропонований алгоритм адаптації ПІ-регулятора, рекомендовані параметри будуть автоматично розраховані та будуть запропоновані оператору. Також можлива реалізація запропонованого алгоритму з автоматичним встановленням розрахованих параметрів ПІ-регулятора.

\section{Висновки}

1. Для використання в промислових умовах розроблено швидкий алгоритм адаптації ПІ-регулятора, який реалізується в реальному часі.

2. Адаптація ПІ-регулятора в режимі реального часу на основі статистичних даних надає системі керування властивостей робастності.

\section{Література}

[1] Штейнберг Ш.Е. Проблемы создания и эксплуатации эффективных систем регулирования / Ш.Е. Штейнберг, Л.П. Сережин, И.Е. Залуцкий, И.Г. Варламов // Промышленные АСУ и контроллеры. - М.: 2004. - №07. - 1-7 с.

[2] Денисенко В. ПИД-регуляторы: вопросы реализации / В. Денисенко. - Современные технологии автоматизации. - М.: 2008. - №1. - 86-99 с.

[3] Ладанюк А.П. Розробка ефективних систем автоматизації технологічних комплексів з використанням методів сучасної теорії керування / А.П. Ладанюк, Л.О. Власенко // Інтегровані технології та енергозбереження. Харьків: 2013. - №3. - 14-20 с.

References

[1] Shteinberg S. Problems of creation and operation of effective control systems / S. Shtein-berg, L. Serejun, I. Zaluckiy, I. Varlamov // Industrial ACS and controllers. - M.: 2004. - №07. - 1-7 p.

[2] Denisenko V. PID-controllers: implementation problems / V. Denisenko. - Modern automation technologies. - M.: 2008. - №1. - 86-99 p.

[3] Ladanyuk A. Development of automation systems of technological complexes using modern control theory / A. Ladanyuk, L. Vlasenko // Integrated technologies and energy saving. - Kharkiv: 2013. - №3. - 14-20 p.

\section{B AUTOMATION NEWS}

\section{The adhesive covering on the basis of extremities structure of a gecko will allow astronauts}

\section{and robots freely to work in space}

The regular adhesive tape can be used several times before it loses the adhesive properties. Besides all such tapes leave sticky marks on on a surface on which dust and other pollutants settles. But researchers from NASA Laboratory on studying of jet propulsion (Jet Propulsion Laboratory, JPL) work on system which is deprived of the shortcomings inherent in an adhesive tape, and it is reached by use of the principles due to which geckoes can keep and move on vertical surfaces.

Thanks to availability on their extremities of a

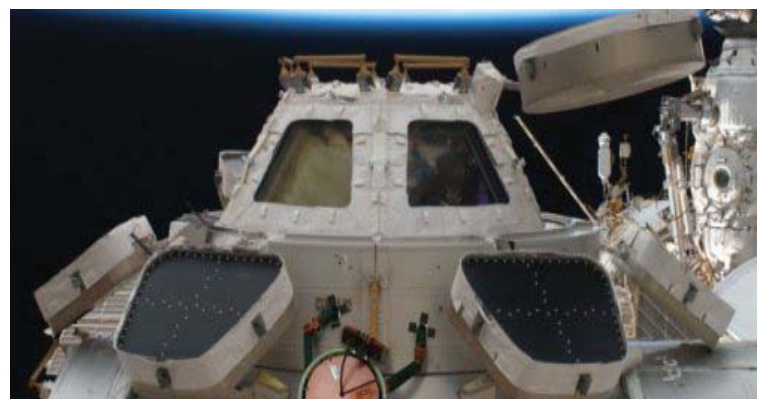
huge number of the thinnest hairs, these lizards can move on walls and in general on any surfaces with complete ease. At the same time, adhesive properties of their extremities don't decrease over time at all. Aaron Parness, the engineer of JPL, together with his colleagues, using the same principle, created the material covered with synthetic hairs which thickness is much less than thickness of a human hair. When such material with some force is put to a surface, hairs are bent and "stick" to it, in accuracy repeating what occurs in case of contact with the surface of an extremity of a gecko. 